\title{
Environmental informatics
}

Computer-based systems for processing environmental information have been in use for more than three decades now. A broad range of applications is covered by these systems, including monitoring and control, information management, data analysis, as well as planning and decision support. Progress in informatics has made an invaluable contribution to our ability to analyse the biological, chemical and physical processes taking place in the environment. Inversely, the complex nature of problems occurring in environmental contexts is a great challenge to informatics. From this process of mutual stimulation, a special discipline has emerged known as Environmental Informatics. It combines computer science topics such as database systems, geographic information systems and simulation modelling with respect to their application to environmental research and protection.

The environmental informatics community maintains an international annual conference series Informatics for Environmental Protection - EnviroInfo that started in 1986. The 20th conference, to be held in Graz, Austria, September 6-8, 2006, will focus on Environmental Knowledge Management.

This special issue contains updated and extended versions of selected contributions to the 19th EnviroInfo held in Brno, Czech Republic, in 2005, as well as additional review papers. The 19th EnviroInfo conference focused on "Networking Environmental Information".

How can environmental information contribute to environmental quality? Besides applications that directly interact with the environment (i.e. control processes at the interface between technosphere and biosphere), the main effect of environmental information is higher environmental awareness both of the general public and of the decision makers in governmental organizations or private companies.

The first six papers in this special issue are directly or indirectly devoted to the task of creating a higher level of environmental awareness by systematically providing information.

The first contribution is a Survey of Environmental Informatics in Europe by Werner Pillmann, Werner Geiger and Kristina Voigt, focusing on the role of environmental information in the political context and summarizing the historic and institutional aspects of Environmental Informatics.

Clemens Düpmeier and Werner Geiger present concepts for the structure, content, and implementation of Environmental
Information Systems for the public, discussing the "Theme Park Environment" as an example.

Michael Stadler, Dirk Ahlers, Renée M. Bekker et al. describe the development of a Web-based data mining tool for analysing data from a plant trait database, an approach to make data mining techniques available for researchers in ecology.

The management of environmental data requires improved data interoperability, data integration and data sharing services. Marcel Frehner and Martin Brändli describe the conceptual design and implementation of the "Virtual Database", an integrated environmental and landscape information system consisting of a framework for advanced Web-based retrieval, analysis, and visualization of spatially related environmental data based on the integration of distributed data repositories.

Information on solar radiation is a critical issue in several environmental domains as well as for energy production by means of solar-powered systems. Since well-controlled measurements of radiation are available only in a limited number of sites, Benoît Gschwind, Lionel Ménard, Michel Albuisson and Lucien Wald developed the "SoDa" Web service based on image processing techniques for extracting solar radiation information from Earth observation satellite images.

Jadranka Pecar-Ilic and Ivica Ruzic describe the development of a specific geographic information system, the "River IS", which provides efficient waterway-related data management for the Croatian part of the Danube River.

Martin Tuchyna reports on the establishment of a Spatial Data Infrastructure (SDI) under the specific conditions of Eastern/Central Europe. A special focus is laid on the environmental sector represented by state institutes managed under the Ministry of the Environment of the Slovak Republic.

The succeeding two contributions have a methodological focus. Jaroslav Pokorný discusses recent advances in database technologies with respect to the requirements of Environmental Information Management Systems (EIMSs). Kristina Voigt, Rainer Brüggemann and Stefan Pudenz show how the Hasse Diagram Technique (HDT), a multi-criteria evaluation method, can be applied to rank environmental chemistry databases.

The last three papers of this issue illustrate the variety of modelling and simulation approaches that can be applied to environmental issues. The first of them by François E. Cellier, Àngela Nebot and Jürgen Greifeneder shows how the heat and 
humidity budgets of "Biosphere 2" are simulated based on a Bond Graph model. "Biosphere 2" is a closed ecosystem located near Tucson, Arizona, designed for studying the interactions between different biological species among each other and with their materially closed controlled environment.

The second modelling and simulation paper by Volker Wohlgemuth, Bernd Page and Wolfgang Kreutzer shows how the model types of Material Flow Networks and Discrete Event Simulation can be integrated conceptually and technically. This approach can be used to support business decisions taking both environmental and economic criteria into account.

In the last contribution, Lorenz Hilty, Peter Arnfalk, Lorenz Erdmann et al. report how a conventional System Dynamics approach to a prospective technology assessment problem proved itself. The goal of the study was to assess the future impact of Information and Communication Technologies (ICT) on environmental sustainability.

The editors would like to acknowledge the support provided by Thomas Ruddy, EMPA, who commented on many of the articles and contributed to this special issue by extensive discussions with authors and the editors. Therese Bracher, EMPA, managed the whole process of collecting and editing the contributions and solved the huge amount of small problems that regularly occur in such a publication project. Last but not least, we would like to thank to the members of the guest editorial board: Werner Geiger, Albrecht Gnauck, Gerlinde Knetsch, Werner Pillmann and Kristina Voigt for their support and their well-considered recommendations.

St.Gallen, Hamburg and Brno.

Lorenz M. Hilty Empa Lerchenfeldstr. 5 CH-9014

St. Gallen, Switzerland

Bernd Page*

University of Hamburg Fachbereich Informatik Vogt-Kölln-Str. 30 D-22527 Hamburg Germany

*Corresponding author.

Jiří Hřebíček

Centre of Biostatistics and Analyses Faculty of Medicine and Faculty of Sciences Masaryk University Kamenice 126/3, 62500 Brno Czech Republic

3 May 2006

Available online 25 July 2006 